\title{
Matemática e Teatro: saber matemático na produção do espaço cênico
}

\author{
Matemática y Teatro: conocimiento matemático en la \\ producción de espacio escénico
}

\section{José Everaldo de Oliveira Vasconcelos ${ }^{1}$}

\begin{abstract}
RESUMO: Este artigo de relato de experiência trata de uma narrativa autobiográfica acerca de um processo criativo nas artes cênicas, desenvolvido na Universidade Federal da Paraíba. Os dados são parte das memórias do autor, no que se refere a experiência de produção de espaços cênicos, que incorporam os números no ato de criação de cenas no teatro, estes representando as personagens, bem como as relações estabelecidas entre um, dois, três, quatro ou cinco personagens ou mais nas subdivisões do elenco e como auxiliam no trabalho criativo, que de algum modo tem influência dos trabalhos de Carrol $(1982,1913)$ e Descartes (1983). Os resultados abordam sobre um modo pessoal de uso de estruturas matemáticas como entes vivos para compreender como as subjetividades das personagens produzem os conflitos e criam o espaço cênico em que atuam e existem. A narrativa autobiográfica apontam para aproximação de assuntos da matemática, aplicados às artes cênicas, como um recurso que envolve a imaginação, a contemplação da natureza e o uso do saber matemático como uma ponte na produção artística.
\end{abstract}

Palavras-chave: Matemática; Teatro; Espaço Cênico; Narrativa Autobiográfica.

RESUMEN: Este artículo del informe de la experiencia trata de una narrativa autobiográfica sobre un proceso creativo en las artes escénicas, desarrollada en la Universidad Federal de la Paraíba. Los datos son parte de las memorias del autor, con respecto a la experiencia de la producción de espacios escénicos, que incorporan los números en el acto de crear escenas en el teatro, estas representando a los personajes, así como las relaciones establecidas entre uno, dos, tres, cuatro o cinco personajes o más en las subdivisiones del elenco y cómo ayudan en el trabajo creativo, que de alguna manera tiene influencia de las obras de Carrol $(1982,1913)$ y Descartes $(1983)$. Los resultados abordan una forma personal de utilizar las estructuras matemáticas cómo seres vivos para entender cómo las subjetividades de los personajes producen los conflictos y crean el espacio escénico en que actúan y existen. La narrativa autobiográfica apunta a la aproximación de los temas de las matemáticas, aplicados en las artes escénicas cómo recurso que involucra la imaginación, contemplación de la naturaleza y el uso del conocimiento matemático cómo una puente en la producción artística.

Palabras Ilave: Matemática; Teatro; Espacio Escénico; Narrativa Autobiográfica.

\section{INTRODUÇÃO}

A primeira versão deste texto foi escrita para atender ao convite de Juliana Souto Lemos, professora do Curso de Graduação em Teatro da Universidade Federal do Amapá para apresentar trabalhos no IV Seminário de Artes Cênicas no Amapá - SAC/AP2, ocorrido de 23 a 27 de abril de 2018, na cidade de Macapá.

\footnotetext{
${ }^{1}$ Mestre em Artes Cênicas pela Universidade Federal da Bahia, Professor Assistente da Universidade Federal da Paraíba, Departamento de Artes Cênicas, Centro de Ciências Humanas Letras e Artes, Campus I, everaldovasconcelos@hotmail.com.

2 https://www.even3.com.br/seminariodeartescenicasdoamapa.
} 
Participei deste evento, ministrando a Palestra: Matemática e Criação Cênica: Relato de uma experiência e a Oficina: Matemática e Criação Cênica, o qual se realizou concomitante ao III Seminário de Políticas Públicas para Educação Penitenciária no Estado do Amapá: Arte, Cultura e Educação Penitenciária - SPPEP/AP ${ }^{3}$.

A Juliana Souto Lemos soube que trabalho com matemática e teatro através da professora Tainá Macedo Vasconcelos, minha filha, porque já tinha mostrado algumas vezes à ela, como usar este recurso em processos criativos, isto é, de tratar a matemática como coisa viva e fazer com que esta auxilie a nossa criatividade.

$\mathrm{O}$ artigo que a revista eletrônica Science and Knowledge in Focus publica é resultado da palestra ministrada e das memórias compartilhadas com os participantes da quarta e terceira edições do SAC/AP e SPPEP/AP.

\section{METODOLOGIA}

O artigo resultado de pesquisa autobiográfica que volta-se a registrar as memórias do autor e a sua experiência sobre processo criativo nas artes cênicas, que faz parte de trabalho desenvolvido no magistério superior, na Universidade Federal da Paraíba, numa abordagem que aproxima Matemática e Teatro.

Na elaboração desta estratégia de pensamento, os trabalhos do matemático e escritor inglês, Lewis Carroll (1982 e 1913), Alice Adventures in Wonderland e Through the Looking Glass, que abordam com maestria o pensamento matemático em sua narrativa, codificado por trás de todas as aventuras, me influenciaram na produção de espaços cênicos, bem como a quarta regra do método de investigação dedutiva (DESCARTES, 1993), a regra da enumeração, a qual tenho aplicado durante a produção de textos para cenas de teatro.

\section{O SABER MATEMÁTICO COMO FERRAMENTA DE TRABALHO CRIATIVO NO TEATRO}

\subsection{A matemática na vida pessoal}

A matemática entrou em minha vida pelo caminho da imaginação. Eu era um péssimo aluno com notas horríveis e não via na matemática nenhum atrativo, tinha apenas a experiência dolorosa de professores que pareciam não se importarem com os seus alunos. Eram um amontoado de cálculos e regras sem qualquer ligação com a vida. Era algo fora da vida, não era divertida, era sinônimo de coisa dura, exata como uma flechada, servia para tornar as coisas mais materiais, tudo era muito previsível. Estudava e passava pelas provas decorando as fórmulas e os macetes para nos livrarmos daquilo, o mais rápido possível.

Somente tempos depois quando entrei na escola técnica, para estudar eletrotécnica é que as coisas começaram a mudar graças a um professor chamado Miguel Levino,

3 https://www.even3.com.br/ppeparte. 
registro aqui o seu nome como homenagem a tantos outros professores de matemática que sabem encantar os seus alunos. Lembro-me que ele fez no primeiro dia de aula uma avaliação de nossas deficiências e disse algo surpreendente, e eu lembro bem, numa situação muito ruim, mas ele não apavorou ninguém, ao invés disso começou a introduzir os assuntos das aulas com muitas histórias sobre os egípcios, sobre o universo, sobre os extraterrestres e nos avisou que a via para adentrar aquele mundo de imaginação era com a linguagem secreta que a matemática possibilitava, mas como tínhamos muitas deficiências ele aconselhou que fôssemos a biblioteca e estudássemos os livros didáticos de Ari Quintela, e resolvêssemos todos os exercícios e então iríamos cada vez mais fundo naquele universo paralelo.

Foi a partir dele que aprendi a ver as coisas da matemática como uma linguagem da imaginação, da mesma forma que temos a língua portuguesa e outros idiomas que nos possibilitam também adentrar neste universo. Também a matemática tinha o mesmo poder e tinha a vantagem de ser uma língua universal falada por todos os povos dos universos paralelos.

A partir daquela visão começou toda uma nova compreensão da matemática. 0 número passou a ter outra significação, os números passaram a ser grandes países, magníficos. Também aprendi com ele que a matemática era a cura para as nossas dores físicas e espirituais, e recordo que nos contou a história de Blaise Pascal (1623-1662), que curava as dores de dentes estudando matemática.

Nunca fui um matemático no sentido correto do termo, mas a matemática passou a ser um dos recursos fundamentais à minha saúde física e mental. Ainda hoje, quando me sinto péssimo, sento-me em um recanto e vou estudar algum assunto da matemática para me curar. Tem dado certo!

Também por Miguel Levino conheci Rene Descartes (1596-1650) e a ideia de que há uma ponte entre a linguagem da matemática e o mundo todo que nos rodeia, pelo seu Discurso do Método. Naquele primeiro ano de escola técnica, eu também me interessei por física, e seguindo a ideia da ponte que a linguagem matemática me proporcionava, me tornei no segundo e terceiro ano monitor do Laboratório de Física da Escola Técnica Federal. Era uma atividade muito divertida, pois, tinha de acompanhar todas as turmas de física no laboratório em experiências acerca dos conteúdos dados em sala de aula, mas também como ficava no laboratório, podia fazer todos os experimentos dos kits de física que lá haviam. Acho que foi a coisa mais linda que me aconteceu, pois, de um lado tinha a matemática e do outro a física como lugar natural daquela linguagem, foi o paraíso.

Mas, onde estava o teatro? Bem, o teatro era para mim uma atividade de infância, uma brincadeira de fundo de quintal, tanto teatro como cinema. Então, fazia teatro para me divertir junto com a minha turma, também brincávamos de outras coisas, mas sempre sobrava tempo para a brincadeira de representar, chegamos a construir um pequeno teatro nos fundos de minha casa, tudo coisa de menino. Quando a matemática entrou em minha vida, um pouco junto com a física, isto na escola técnica, o meu brin- 
quedo teatral tomou um rumo diferente, pois, aquilo que era somente pura intuição artística, agora tinha para mim uma possibilidade de linguagem.

Eu tinha aprendido que a matemática me proporcionava um jeito mais vivo de entender todas as coisas, isso teve a participação de um outro docente da escola técnica, o professor de física, João Medeiros; eu era o seu monitor no Laboratório de Física. Nos momentos em que não havia alunos ele desenhava no quadro as equações de seu trabalho de pós-graduação sobre o movimento de partículas atômicas, e então ia lendo para a mim a história das partículas em sua vida própria através do simbolismo matemático.

A equação era como um livro de histórias. Acho que ele precisava de um ouvinte para falar de seus estudos e eu era o ouvinte perfeito. Aquilo mudou a minha e a forma de ver as fórmulas matemáticas. Se eu pudesse olhar com atenção e imaginação cada equação, daí vinha inspiração para contar histórias. Eu aprendi também que a natureza pede uma matemática para ser vista, então, uniram-se fatores muito interessantes: imaginação, contemplação da natureza e o uso da matemática uma como ponte.

A natureza fala conosco numa linguagem matemática. Também foi naquele momento que aprendi que devíamos ser flexíveis quando estamos lidando com a natureza. Se uma equação não funciona, então temos que cortar o que não serve, e procurar outra coisa que se adapte melhor, quer dizer, a matemática não era para ser uma prisão, mas uma ponte de libertação. O professor Medeiros me contava que havia alguns matemáticos que se irritavam com esse tipo de procedimento dos físicos, ele me explicava que cada coisa tinha o seu lugar, mas quando lidamos com a natureza devemos fazer a operação inversa e escutar as equações que a natureza nos ensina. Assim aprendi que observando com carinho podemos ver as equações que a natureza nos mostra em tudo, inclusive no teatro, que é um lugar de acontecimentos matemáticos formidáveis.

Aprendi a visualizar os fatos matemáticos como entes vivos. Quando observamos o acontecimento nós vemos as relações entre as coisas, mas não temos aquela caixinha preta cujo funcionamento dá origem àqueles relacionamentos. Por exemplo, um grupo de pessoas está conversando, cada pessoa é uma coisa que tem vida própria, a conversa é uma coisa dependente das pessoas, existem também coisas independentes como o ambiente e outras coisas que influenciam na conversa. Existe uma caixa preta que contém todas estas coisas funcionando. O brinquedo é encontrar através da linguagem matemática algo que seja parecido. Quando a gente trabalha no plano da imaginação pura, é fácil brincar com estas coisas, mas nem sempre é fácil descer até a formalização.

Há alguns anos atrás brincando com experimentos interativos para tv digital, fui convidado pelo diretor da TV UFPB para criar o protótipo de um programa interativo para a tv digital. Aceitei a proposta e desenvolvi um procedimento que possibilitava a construção de algo cujo desenvolvimento entre o início e o fim poderia ter muitas possibilidades dependendo de cada espectador. Seguindo o caminho primeiro fui para o mundo de imaginação e construí a caixa preta, os seus elementos e as coisas todas, na ponta eu desenvolvi um roteiro possível de ser gravado com os recursos que tinha, que 
eram zero oitocentos, isto é, do próprio bolso.

Fiz o roteiro, trabalhei com combinatória e matemática elementar, mas quando tentei descrever o modelo de modo formal, vi que havia me perdido de meu treinamento matemático, pois tinha deixado para trás o bacharelado em matemática pelo teatro. Então, entrei na Licenciatura em Matemática a distância, dentro de minhas possibilidades de tempo, como modo de disciplinadamente retomar o treinamento para poder minimamente formalizar para mim mesmo o que conseguia ver com absoluta clareza no mundo da imaginação.

Eram famílias de possibilidades que depois de escritas numa formulação simples davam a mesma sensação das equações do professor Medeiros. É bonito de se ver estas coisas funcionando. Matemática exige treinamento constante. Por isso esclareci no início de que não sou um matemático, pois falta-me a constância de seu exercício formal, porque em um determinado momento eu me transferi para a atividade teatral, e de um jeito muito particular continuei a praticá-la em um reino de imaginação pura.

Do mesmo modo, algumas pessoas conseguem ver as cores de uma música, eu consigo ver as coisas matemáticas a partir de uma visão pessoal. Por isso, muitas vezes, dizia aos meus colegas que não precisava de nenhum alucinógeno para me divertir, se eu parar um pouquinho diante de algo eu consigo ver a matemática da coisa. Acho que foi algo que descobri por acaso influenciado pelos dois professores que já citei, e como é algo que me tira do mundo, e produz uma sensação boa, foi ficando como um hábito. É como andar de bicicleta, fez uma vez, fica valendo à vida toda.

\subsection{O número}

Tudo aquilo que tem existência torna-se um número, um número é algo muito maior que somente aquilo que estudamos nas instituições escolares. Aprendemos a ver o número como uma quantidade ou uma medida de algo. Mas retomando a ideia da caixa preta de que falamos antes, o número pode ser algo como aquela caixa preta. Ele pode conter outras coisas e num determinado conjunto numérico comportar-se de uma maneira e em outro não, o que se justifica pela regras de diferentes tipos de números e sistemas de numeração antigos e atuais ${ }^{4}$, enquanto que no contexto da produção do trabalho criativo, como um espaço cênico pode ter outras aplicações.

A primeira coisa que transpus para a minha atividade de criação foram os números naturais, isto é, $N=\{0,1,2,3,4,5 \ldots\}$ ou $N^{*}=\{1,2,3,4,5 \ldots\}$. Estes que podemos contar com os dedos, um dois, três, etc. Num primeiro exercício, aprendi que todos no grupo de teatro eram um número. Todos eram um número um, sozinhos em sua vida e rito; comportavam-se como um. Imaginei também que o palco era um lugar que afundava com os números, então cada número um produzia um afundamento.

O palco é um lugar mole e imaginei que quando dois e um estabelecem relações entre si, eles afundavam o palco, produzindo uma espécie de canal entre eles e qualquer

${ }^{4}$ IFRAH, G. Os Números: A história de uma grande invenção. Trad. Stella M. de Freitas Senra. 11.ed. São Paulo: Globo, 2005. 
coisa que passasse por este canal, escorrega para um ou para outro. Este equilíbrio somente é alterado pelo movimento de um desses uns, uma da coisa que atravessou.

Se houver no palco três números, um forma-se entre eles uma estrutura de canais do mesmo jeito que o anterior. Se dois e um ficam muitos próximos, então eles passam a se comportam como um dois em relação ao outro um que ficou sozinho e eles vão ter mais poder de ter as coisas escorregando para eles. Então, descobri que os entes sobre o palco podem ter nomes diferentes de um, assim um ator pode ter número dois, outro um, e outro cinco por exemplo. Assim, entendi que cada personagem pode ter mais camadas que a outra e que cada camada é um número um.

Personagens mais simples podem ter nome de número um, e personagens mais complexos podem ter um número maior.

Agora tem uma outra camada que precisa ser visualizada, que é algo que podemos chamar de tempo, mas este é um nome ruim para trabalhar com estas imaginações, porque tempo está associado a duração em comparação com algum relógio, seja qual for. Neste reino de imaginação não funciona assim.

Novamente pedindo licença, imaginem que cada coisa, a cena que estamos estudando já existe toda num bloco só de coisas. O que faço é fatiar esta coisa grande em fatias que contém as configurações, a coleção de fatias é o que chamamos de tempo. Então, o tempo depende do modo como fatiamos a coisa grande.

Usando o exemplo de uma cena, quando eu paro diante dela e faço aquele exercício, eu vejo a coisa grande lá, mas não tem como trazer aquilo para o real, então a gente fatia aquilo. A fruição sequencial é uma opção, pode ser simultânea, e podem existir seres no universo que tenham uma fruição simultânea de muitas fatias. É uma característica humana fruir fatias uma após a outra. As várias picturizações das cenas que estabelecemos como marcações e construções visuais são estas fatias.

Voltando ao modo como os números foram se misturando ao meu fazer teatral. Quando comecei a contemplar as personagens e suas complexidades, aprendi que algumas poderiam ter outras relações com os seus números, e então veio-me em socorro a noção de números relativos, e que as vezes ganhar números poderiam significar uma perda. Anos depois quando aprendi a brincar com Role Play Game - RPG ${ }^{5}$, vi que no sistema de construção e manutenção de personagens havia um tipo de pontuação semeIhante. Tinha coisas que se agregavam a uma personagem, mas faziam ela perder força. Estas coisas que se agregavam eram elementos que passavam a compor aquela personagem.

Numa encenação eu posso dar força ou tirar força de uma personagem agregando coisas a ela ou retirando coisas. E daí, eu ficava sempre me perguntando quando estava criando uma cena, se aquilo agregava ou retirava força, e esse raciocínio me veio do brinquedo com os números relativos no processo de criação.

Os números racionais, $Z=\{\ldots-5 / 1,-5 / 10,0,+5 / 10,+5 / 1\}$, para um campo mais ri-

5 Para saber sobre a dramatização no ensino e aprendizagem da ciência, ver: MCSHARRY, G.; JONES, S. Role-play in science teaching and learning, School Science Review, Hatfield, v. 82, n. 298, p. 73-82, Sept. 2000. 
co de interações me ensinaram que tem coisas que se agregavam e faziam um estrago muito grande. Por exemplo, se eu tivesse uma personagem com um número em forma de fração, por exemplo, 5/1 e outro se agregasse a ele dividindo, por exemplo 10, ele ficaria 0,5 ; ou fazem mais em potencial, por exemplo se a personagem com um número em forma de fração, por exemplo, 5/1 e outro se agregasse a ele multiplicando, por exemplo 10 ele ficaria 50.

Então, muitos personagens simples poderão ter uma descrição como um número racional. Mas então nós descobrimos que existem personagens que não podem ser descritos assim, são um poço sem fundo, as personagens do mundo real são um poço sem fundo, elas são como os números irracionais, mas elas podem ser descritas por relações simples, como raiz quadrada de dois ou pi, por exemplo, que em linguagem matemática são representado por $\sqrt{ } 2$ e $\pi$.

E daí fomos para o reino dos números reais. Eles resolvem quase tudo, mas quando entramos em coisas mais miúdas, vemos que seria útil lidar com coisas impossíveis nos reais, e usar a ideia de que aquela personagem tem uma parte real e outra imaginária, me fez usar a ideia de número complexo, isto é, $Z=x+y . i$, onde " $x$ " e " $y$ " são números reais e "i" é a unidade imaginária com a propriedade que $\mathrm{i}^{2}=-1=\sqrt{ }-1$ (IEZZI, 1977), e suas extensões para brincar com as personagens no mundo imaginário, levando em consideração as camadas profundas do inconsciente.

É claro que, quanto mais refinamento e treinamento matemático eu tinha, mais estas imaginações eram usadas com mais acuidade. Uma coisa interessante foi incorporar a noção de matriz a uma personagem, porque ao invés dela ter números que chegavam e operações que conduziam a sua transformação, uma personagem poderia ser uma matriz com um conjunto de números. Daí, a coisa ficava mais linda por que cada personagem era uma matriz e todas as coisas também eram matrizes, cada qual cheia de possibilidades de relacionamento.

Tudo ficava muito mais arrumado. E o mesmo jogo com o palco mole, que se tornava mais elegante, pois o próprio palco em sua "moleza" (não tenho um outro nome para isso) era uma matriz com um monte de possibilidades. E então surgiu uma ideia muito engraçada e natural: $E$ se as personagens não fossem fixas, mas se mexessem dentro delas mesmas, onde cada número da matriz na verdade, fosse uma função de alguma coisa e estivessem sempre mudando?

E veio a ideia básica de que o espetáculo é uma grande função, cujas variáveis recebiam matrizes e retornavam uma matriz que é a fatia da qual falamos antes.

\subsection{O espaço cênico}

O espaço cênico ${ }^{6}$ tomou um rumo diferente do conceito geográfico elementar.

\footnotetext{
${ }^{6}$ Para a discussão sobre espaço cênico, ver: PIRES, A. T. C. A Poesia do Espaço Cénico: contributo para uma reflexão sobre a participação das artes plásticas e da música/som na construção do espaço cénico contemporâneo. (Dissertação de Mestrado). Faculdade de Letras da Universidade do Porto, 2017.
} 
Geralmente, consideramos o espaço cênico como um lugar físico com medidas, que tem os seguintes elementos: urdimentos, o palco e o porão (ARAÚJO, 2013). Mas começamos a ver o espaço cênico como algo muito mais abstrato. Apesar de sua existência, ele tem duas maneiras de abordagem, de um lado aquilo que é comum, e de outro lado, um conceito muito mais amplo.

Um espaço cênico seria um ente que obedeceria a algumas regras simples: todo o relacionamento dentro do espaço cênico deveria permanecer dentro dele; um espaço cênico deveria se ligar completamente; um espaço cênico seria continuo dentro de seus limites, mesmo que no aspecto físico ele aparentasse descontinuidade. É tanto que, do ponto de vista físico, falamos em espaços cênicos contínuos e descontínuos.

E também que haveria um espaço cênico amplo e um espaço cênico restrito. $O$ espaço cênico amplo seria aquele que conteria os atores e espectadores; o espaço cênico restrito seria aquele que conteria a cena teatral, ou o que costumamos chamar de palco, o lugar da cena. Em ambos os casos temos a continuidade e descontinuidade, no aspecto físico, mas no plano abstrato estes espaços somente adquiririam o status de serem cênicos se fossem contínuos e se todos as interações entre eles permanecerem dentro dele.

Esta forma de pensar o espaço foi algo que veio por analogia com os espaços vetoriais. Também com esta ideia de vetores é que começamos a entender o relacionamento entre cena e espectadores como vetores de atenção. Um espetáculo funcionando é como se fosse um grande campo de energia e se fosse possível ver, veríamos estes vetores!

\subsection{Na aproximação das pessoas do grupo teatral}

$\mathrm{Na}$ aproximação das pessoas do grupo teatral para montar uma peça de teatro, inspiro-me na quarta regra do método de investigação dedutiva (DESCARTES, 1993), a regra da enumeração e faço a numeração de todos os elementos do texto.

Primeiro numeramos as falas de todas as personagens, depois os movimentos do texto. Chamamos de movimento os pequenos pedaços do texto e sua estória, obedecendo ao critério pessoal, de como vemos aquela encenação; em alguns casos esta subdivisão do texto remete a conceitos dramatúrgicos ou semiológicos. A regra que usamos é a nossa intuição de como deveria ser cada pequena peça do quebra-cabeça maior.

Uma vez que estou indo para dentro de minha imaginação, então tenho que me manter fiel a esta realidade e universo, mas não discuto as coisas matemáticas com o elenco, apenas mostro as subdivisões e como elas facilitam o trabalho criativo.

\section{CONSIDERAÇÕES FINAIS}

A pesquisa autobiográfica aborda sobre um modo pessoal de uso de estruturas matemáticas como entes vivos para compreender como as subjetividades das persona- 
gens produzem os conflitos e criam o espaço cênico no qual atuam e existem, o que faz parte das atividades que desenvolvo no magistério superior, como professor do Centro de Ciências Humanas Letras e Artes, vinculado ao Departamento de Artes Cênicas da Universidade Federal da Paraíba.

A literatura sobre criatividade é vasta de recursos com múltiplas linguagens e abordagens nas Artes Cênicas, Teatro e Educação, além de ser debatida em outras ciências e áreas de pesquisa. Assim, este artigo relata uma parte do processo de raciocínio criativo na produção de espaços cênicos, o que pratico pelo exercício de visualizar os entes matemáticos com emoções e características de um ser vivo na arte cênica.

A narrativa autobiográfica apontam para aproximação de assuntos da Matemática, aplicado às Artes Cênicas a partir de um recurso que envolve imaginação, contemplação da natureza e o uso da saber matemático como uma ponte na produção artística.

\section{REFERÊNCIAS}

ARAÚJO. L. Vídeo: Os Elememtos do Espaço Cênico. Disponível em: ttps://karinafacenda. wordpress.com/2013/11/11/elementos-do-espaco-cenico/, Acesso: 29/30/2018.

CARROL, L. Alice adventures in wonderland. London: Macmillan and co. Limited, 1913. . Through the Looking Glass. London: Puffin Books, 1982.

DESCARTES, R. O Discurso do Métodos. Trad. J. Guinsburg \& B. P. Júnior. 3. ed. São Paulo: Abril Cultural, 1983.

IFRAH, G. Os Números: A história de uma grande invenção. Trad. Stella M. F. Senra. 11. ed. São Paulo: Globo, 2005.

IEZZI, G. Fundamentos da Matemática Elementar: Complexo, polinômios e equações. 2.ed. São Paulo: Atual, 1977.

MCSHARRY, G.; JONES, S. Role-play in science teaching and learning, School Science Review, Hatfield, v. 82, n. 298, p. 73-82, Sept. 2000.

PIRES, A. T. C. A Poesia do Espaço Cénico: contributo para uma reflexão sobre a participação das artes plásticas e da música/som na construção do espaço cénico contemporâneo. (Dissertação de Mestrado). Faculdade de Letras da Universidade do Porto, 2017.

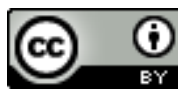

License information: This is an open-access article distributed under the terms of the Creative Commons Attribution License, which permits unrestricted use, distribution, and reproduction in any medium, provided the original work is properly cited.

Article received on June 15, 2018.

Accepted on October 30, 2018. 